\title{
National Identity in Business Communication and Professional Ethics
}

\author{
Ildus Islamovich Zaylalov \\ Department of Humanities and Socio-Economic Sciences \\ Ufa State Petroleum Technological University, Branch of \\ the University in the City of Oktyabrsky \\ Oktyabrsky, Republic of Bashkortostan, Russian Federation \\ e-mail: ildus.61@ mail.ru
}

\begin{abstract}
- the paper considers the analysis of social and humanitarian research related to the national identity, which has an impact on the structure of business communication and professional ethics in a multinational society. Global processes, integration of different countries, ethnic groups, cultures and civilizations have directly led to changes in different forms of identities within the process of personal and group communications. One of the solutions to intercultural and inter-ethnic relations, by which the qualitative level of business communication in a multinational society was determined, is the professional environment as a center for potential achievement of global consensus and multicultural unity among the representatives of different national cultures. The reflection of this process raises the problem of increasing the role of business communication and professional ethics as alternatives in solving inter-ethnic problems. The study of this problem provides an opportunity to objectively consider personal psychological and social problems within different forms of communication. This analysis may subsequently affect the awareness of its importance in new socio-cultural conditions of professional activity.
\end{abstract}

Keywords - national identity, business communication, professional ethics, socio-psychological aspect, rational and irrational in consciousness.

\section{INTRODUCTION}

Computer technologies and their constantly developing opportunities in developing political, economic, sociocultural and inter-ethnic relations made it possible to expand educational and scientific potential in the studied objects and their processes. The adoption of non-standard decisions and non-traditional approaches in the globalizing world allowed creating new forms of business communication with the increasing role of interaction of the interdisciplinary in the educational space and the intersectoral in the industrial complex. The new paradigm of integrity and integrativeness in social relations, awareness of the need for global processes and a comprehensive view of the world, the emergence of a new conceptual apparatus that promotes humanitarian research in the field of business communications - all this leads to changes in the content of categories of rationality and irrationality within the interaction of objects and subjects from the position of public consciousness. Strengthening the importance of non-

\author{
Venera Rifmirovna Zaylalova \\ Department of Information Technologies, Mathematics and \\ Natural Sciences \\ Ufa State Petroleum Technological University \\ Branch of the University in the City of Oktyabrsky \\ Oktyabrsky, Russian Federation \\ e-mail: venera-zajlalova@mail.ru
}

traditional means and methods of communication study in the field of professional activity, awareness of mechanisms of understanding the reality through various forms of communication is today a significant understanding of the objectivity of these processes in the creation of "professional ethics".

The process of business communication involves not just individuals, but individuals with a national identity, who influence business communication in large and small professional groups, who solve the same problems, but who have their own vision of problems from the position of national interests in the business sphere. The concepts of single and collective actors can be applied to them. A single subject is an individual as a carrier of certain professional properties, i.e. a specialist, and the collective subjects should include various professional communities where professional activities are carried out. The interaction of subjects creates certain levels (cultural, national, social, etc.), of which consideration is important for understanding the different technologies of interaction and patterns of professional communication itself. Considering the professional context of business communication development from the point of view of the national identity of its participants, it is necessary to take into account, first of all, the social component, i.e. "professional ethics". This is particularly important when the professional environment is filled with intercultural and inter-ethnic interaction. Professional interests offset national interests, but the process of unification can over time intensify contradictions between its participants, possessing a national identity, if this is not paid close attention by philosophers, psychologists, sociologists and cultural scientists.

\section{LITERATURE REVIEV}

The studies of G. De Vos [1] draw an immediate parallel between the national identity and the socio-economic status of the human person, which in our opinion is the basis for professional communication, and therefore the socialization of the human being in the future. Popular ideas of "symbolic interactionism" and "the theory of ego identity" in the United States of America were based on the assimilation concept typical for the state due to its historical development. They formed the basis for G. De Vos's 
be structurally interlinked and consistent with universal human values.

In this direction the work of Adam Curle [6], who uses the term "identity of understanding" to define the personal identity and "identity of accessory" - for social identity, seems the most interesting. In our view, "identity of accessory" is that conscious sphere where "professional ethics" feels much more stable and confident due to "comprehensiveness" of traditional values, which it psychologically tries on itself ("this is my land", "this is my home", "this is my family", "this is my work"). Thus, this form of awareness is best understood by the representatives of other national communities who recognize their uniqueness. "Professional awareness" is the recognition by a person of its involvement in general professional activity. Only the process of business communication applies these two forms as the development of new psychological skills to understand social processes, cultural transformation and correlation with own values and universal moral orientations. But at the same time transformation implies selective transfer into the own system of behavior and relations of those norms and rules of business communication, which are adopted in a given society or a professional group. This vision of the problem involves the use of the concepts of personification and personalization isolation or individualization, which impact business communication mainly at emotional and cognitive levels. However, to date the ratio of external to internal perception of business communication remains open, as it does not affect the behavioral component of professional ethics from the position of irrational in the consciousness of single subjects. Prejudices, stereotypes, mentality, customs, manners, etc., are the real mechanisms that prevent the most effective construction of the system of business relations and the definition of the essence of professional activity.

Summarizing this problem, it is possible to cite the idea of S.L. Rubenstein, who in his work A Man and the World said that the "relations" between people, their ability to understand each other and the desire to constantly build and establish them constitute the core of human life [7]. The central, systemic characteristic of a person is recognized as the ability and desire of a person to build relations with another person. The above can be a starting point for considering new business communication relations between its various representatives, taking into account national characteristics, as a wider system in modern sociocultural communities. This makes it possible to identify significant options for building more effective structures of business relations, and hence of professional ethics in the process of globalization of the multinational community. At the present stage of society development, business relations are increasingly based on the variability of solving various problems with the preservation of national interests, but with compliance with international legal norms.

These communications are mainly formed in the process of personal contact between different subjects (state and spiritual leaders, corporate executives, general managers, etc.). For several reasons they may be forced (migration processes, military conflicts, environmental disasters, etc.) 
This concept is mainly related to social development and is of interest in the description of inter-ethnic and interpersonal communications, where professional ethics and business communication can be considered as subjects of cultural space, contrary to or complementary to modern globalization processes [11]

\section{DISCUSSIONS}

The theoretical significance of this paper lies in the analysis and development of a new vision of relations between the concepts of "business communication" and "professional ethics" in the context of modern civilizational challenges. This will reveal the specifics of further development of intercultural communities and predict further qualitative development of business communication. The paper reveals the idea of systematizing and developing categories studying "business communication" and related sociocultural and political processes [12].

The practical significance of the study is determined by the fact that the analysis and conclusions of this paper will help to optimize the process of studying this problem in the educational space between the subjects of the Russian Federation. The work can serve as a methodological basis for sociological studies aimed at monitoring the state of interpersonal and intercultural communications in Russia, which has a unique historical experience of inter-ethnic relations between peoples living in its territory. These studies can also be used in the educational process of higher educational institutions and specialized secondary educational establishments [13-16].

\section{RESULTS}

Based on an analysis of the national identity in the structure of business communication it can be argued that:

- Business communication is the most irrational topic in the social and humanitarian sphere, as it is an area where the main stereotypical symbols of professional ethics are formed [17]. National identity is one of the early psychological mechanisms in the field of consciousness. This area most stereotypically instills the ideas about behavior and relations of people, makes them strong and stable, so it is hard to rethink. As a result, "business communication" reflecting real interactions between people remains largely irrational in nature. The categorization "I he" - "we - they" crystallizes various kinds of interpersonal communications, and serves the prism through which the awareness of national identity is refracted. It is the national identity with the help of irrational components that easily mobilizes, quickly consolidates the professional community into defending its interests. This instinctivity, without compliance with international legal norms multiplied by the achievement of profit by any means by world industrial corporations, results in inter-ethnic conflicts that are difficult to predict and solve;

- Individual as a creator and a carrier of various forms of communication defines the main types of rational behavior in professional ethics. Changes constantly taking place in between people, but also as a spiritual element that helps individuals to build and realize this world [10]. However, the civilizational approach served the basis of the study. 
[4] J.Turner, Social Categorization and Self-concept: A social cognitive theory of group behavior, Advances in group processes, vol.2, Greenwich, Connecticut: JAI Press, pp. 77-1216 1985.

[5] G. Pomerants, Meetings with Buber, Moscow: AST,1999.

[6] A. Curle, Mystics and militants. A study of awareness, identity and social action, London:Tavistock publication, 1972.

[7] S.Rubinstein, Man and the world, SPb.:Peter,2012.

[8] A. High, D. Solomon, "Explaining the Durable Effects of Verbal Person-Centered Supportive Communication: Indirect Effects or Invisible Support," Human Communication Research, vol. 42 iss. 2, pp.200-220, 2017.

[9] A. Zaripov, I. Zaylalov, The search for identity in the postmodern era: axiological paradoxes of ethnic identity Ufa: USPTU, 2017.

[10] C.Colaner, J. Soliz, Communication-Based Approach to Adoptive Identity: Theoretical and Empirical Support Communication Research Human Communication Research, vol. 44 iss. 5, pp.611-637, 2017.

[11] G. Neubaum, N. Krämer, "Opinion Climates in Social Media: Blending Mass and Interpersonal Communication," Human Communication Research, vol. 43 iss. 4, pp. 464-476, 2017.

[12] J.Dibble, T.Hartmann, S.Rosaen,"Parasocial Interaction and Parasocial Relationship: Conceptual Clarification and a Critical Assessment of Measures", Human Communication Research, vol. 42 iss. 1, pp.21-44, 2016.

[13] E.Guseinova, "Organizational and pedagogical conditions for the development of professional competencies in the technical students' individual work through the example of studying the discipline «Hydraulics and fluid mechanics»", European Journal of Contemporary Education, No(1), pp.118-126, 2018.

[14] E. Mukhtasarova, "State of modern russian youth tolerance", European Proceedings of Social and Behavioural Sciences, vol. 50, pp. 206-213, April 2018 (RPTSS 2018, p. 1464, 2018).

[15] R.Yusupov, "Resource of russian religious and philosophical tradition in constructive relationship with west", European Proceedings of Social and Behavioural Sciences, vol. 50, pp. 1402-1408, April 2018 (RPTSS 2018, p. 1464, 2018

[16] R.M. Shaidullina, A.F. Amirov, V.Sh. Muhametshin and K.T. Tyncherov, "Designing economic socialization system in the educational process of technological university," European Journal of Contemporary Education, vol. 6, no. 1, pp. 149-158, 2017 DOI: 10.13187/ejced.2017.1.149

[17] R.Obregón, T. Tufte, "Communication, Social Movements, and Collective Action: Toward a New Research Agenda in Communication for Development and Social Change," Journal of Communication, vol. 67 iss. 5, pp.635-645, 2017.

[18] V.Zaylalova, I. Zaylalov, "The process of self-identification of foreign students at the Technical University," SHS Web of Conferences, vol. 69, pp.1-5, 2019.

[19] A. Flanagin, A. "Online Social Influence and the Convergence of Mass and Interpersonal Communication," Human Communication Research, vol. 43 iss. 4, pp.450-463, 2017. 